\title{
Effect of Particle Loading, Temperature and Surface Treatment on Moisture Absorption of CFB Fly Ash Reinforced Thermoset Composite
}

\author{
Sakura E. Onishi
}

\begin{abstract}
Coal combustion is widely used in the Philippines and is a major contributor to power generation due to its low cost; however, it produces wastes such as emissions and fly ash (FA). Traditional fuel combustion uses pulverized coal (PC) boilers while modern technology involves the use of circulated fluidized bed (CFB) boilers which produce less emissions and are more efficient. However, the fly ash produced from CFB combustion has limited application to the construction industry as opposed to PC FA which is used as an additive to the cement industry. In this study, CFB FA is used as filler and the matrix is orthophthalic unsaturated polyester resin. Moisture absorption study is conducted on the composite by immersing in water and constant weighing of samples at specified time intervals. Percent weight gain is reported. Particle loading and sorption temperatures are varied and their effects are observed. With the increase in particle loading, absorbed moisture increases while diffusivity decreases. Increase in temperature leads to an increase in moisture absorption and diffusivity. The CFB FA is also treated using coconut oil which is composed of saturated fatty acids (majority of which is lauric oil). Coconut oil serves as a non-coupling type surface modifier. Untreated and treated fly ash samples are characterized by X-Ray Flourescence (XRF), Scanning Electron Microscopy (SEM) and Fourier Transform Infrared Spectroscopy (FTIR). The effect of treatment to composite moisture absorption at $800 \mathrm{C}$ (different particle loading) is observed and it is found to decrease moisture absorption.
\end{abstract}

Index Terms-CFB fly ash, moisture absorption, particle filled composite, polyester composite.

\section{INTRODUCTION}

Combustion of solid fuels is one of the most widely used source of energy. Worldwide, coal is a sought-after energy source. It is often the cheapest fuel option and has a large reserve. Philippines is a coal consuming country, having coal as one of the major contributors to power generation [1] Energy consumption and generation in the Philippines is increasing and with this power generation from coal will also increase. This will continue to increase as the government promotes clean coal technology, production of coal and establishment of ASEAN Coal Supply Security Agreement. The increase in production of coal is targeted to displace and decrease oil use [2].

With environmental awareness and restrictions, cleaner and more efficient burning of fuel is now available thru the

Manuscript received April 15, 2014; revised June 25, 2014. This work was supported by the Philippine Department of Science and TechnologyEngineering and Research Development for Technology.

Sakura E. Onishi is with the University of the Philippines-Diliman, Philippine (e-mail: sakura.onishi@gmail.com). clean coal technology, wherein circulating fluidized bed (CFB) are used. Circulating fluidized bed combustion (CFBC) boiler can utilise all grades of coal and lignites in an efficient and environmentally clean way (lower emissions) [3].

Combustion of solid fuel has a by-product, fly ash. Conventional pulverized coal (PC) boilers produce fly ash that is traditionally used as an additive in Portland cement production [4]. However, CFB fly ash has limited applications in cement and land restoration [5]. Composition and properties of CFB fly ash is dependent on the type and origin of the fuel used as well as the combustion conditions, and these might not be able to meet set standards [6]. Also according to European Standard, fly ash is defined to be spherical and contain glassy particles. CFB fly ash differs because it is not spherical and the glassy phase is not present [7].

Instead of being disposed in landfills, there are studies that utilize CFB fly ash. Some studies include the use of fly ash as soil $\mathrm{pH}$ modifier [8], for value added pavement construction [9], autoclaved bricks [10] and zeolitic materials [11]. Another potential use of CFB fly ash and the focus of this study is as filler to produce composites. Fillers are generally inert material in composites which help reduce material cost, improve mechanical properties and may improve processability [12]. This research is focused on conducting moisture absorption studies of CFB fly ash reinforced composites. The matrix to be used is orthophthalic unsaturated polyester resin. Unsaturated polyester resin has versatile properties and application. It also does not need high pressure moulding equipment [13] and is capable of curing at room temperature [14]. It is a popular thermoset used as martix for composites [15]. It is widely used because of its processability and good crosslinking tendency. Polyester composites have been used in many applications such as naval construction, waterlines, pipes, shower stalls, corrosion resistant tank, building panels and building constructions [16]. Non-fiber reinforced polyester applications also include sinks, bowling balls and coatings [17].

The use of fly ash as filler is still not widespread because of weak interfacial bonding. A large part of fly ash is composed of silicon dioxide, aluminium oxide and iron (III) oxide, these are polar and make the fly ash hydrophilic while the matrix is hydrophobic. In order to increase interfacial bonding, the surface of the fly ash is modified. There are many studies involving surface modification. There are studies which increase the surface area of the fly ash [18], [19]. Other methods of surface treatment involve 
the use of surface modfifiers, both the coupling agents and non-coupling type such as fatty acids. A study employed the use of a coupling agent silane [20] and a recent study employed the use of stearic acid as to make the hydrophillic CFB fly ash, hyrdrophobic [21]. For this study, fatty acids from coconut oil (mostly lauric acid) will be used to treat the surface of CFB fly ash.

There are limited studies on using CFB fly ash as filler to reinforce thermosets thus its properties have not yet been studied in great detail. The purpose of this study is to investigate moisture absorption behaviour of CFB fly ash filled polymer composite and how it is affected by sorption temperature, particle loading and treatment of fly ash.

\section{MATERIALS AND METHODS}

\section{A. Materials}

The CFB fly ash used in this study was from a pulp and paper plant located in Bulacan, Philippines. The matrix used in all the samples was orthophthalic unsaturated polyester resin, R 10-103, from Polymer Products (Phil) Inc. Polymer hardener (methyl ethyl ketone peroxide) and mold releaser/cleaner (Durawax ${ }^{\circledR)}$ were also procured from Polymer Products (Phil) Inc. Ethanol and sulphuric acid used in treatment of the fly ash was from BE Scientific. Commercially available Minola ${ }^{\circledR}$ Premium Lauric Oil is used as treatment.

\section{B. Chemical Treatment of Fly Ash}

Procedure for treatment is adapted from [21]. $200 \mathrm{~mL}$ of distilled water and $100 \mathrm{~g}$ of fly ash was mixed in a $600 \mathrm{~mL}$ beaker. The $\mathrm{pH}$ of the slurry was adjusted to 8 using concentrated sulphuric acid. In another $600 \mathrm{~mL}$ beaker, $3 \mathrm{~g}$ of coconut oil is dissolved in $60 \mathrm{~mL}$ ethanol heated at $60^{\circ} \mathrm{C}$. The fly ash slurry was slowly mixed with the ethanol-oil mixture. Mixing was done under vigorous stirring at 1500 $\mathrm{rpm}$ and for 30 minutes at $30^{\circ} \mathrm{C}$. The treated fly ash is filtered and washed with hot ethanol $\left(60^{\circ} \mathrm{C}\right)$ until there is no crystal formation in the filtrate. The fly ash is oven dried at $110^{\circ} \mathrm{C}$ for 12 hours.

\section{Composite Production}

Prior to mixture preparation, mold ( $2 \mathrm{~mm}$ thick aluminium flat bars and metal sheets) and plastic film (commercially available as OHP acetate films) were waxed for easier releasing of samples and mold cleaning. The mold was prepared on the heat press as follows: newspaper, metal sheet, plastic film, aluminium flat bars. The press was turned on and pre-heated to $55^{\circ} \mathrm{C}$ for 15 minutes.

Orthophthalic resin was mixed with $1.5 \%$ by weight MEKP hardener in a PET container. CFB fly ash with varying compositions $(10 \%, 30 \%, 40 \%)$ was then added to the mixture. The resin-fly ash mixture was mixed using a hand mixer at maximum speed for 5 minutes. After mixing, the resin-fly ash mixture was de-aired using a vacuum dessicator until there were no visible air bubbles in the mixture. The resin-fly ash mixture was poured into the mold. Plastic film was then carefully placed, preventing formation of air bubbles. Metal sheet was placed over the plastic film, followed by newspaper. The press was then closed and maintained at $55^{\circ} \mathrm{C}$ for 6 hours.
The composite was released from the mold and the rectangular slab was cut to samples with dimensions of $4 \mathrm{~cm}$ $\times 2 \mathrm{~cm}$. Edges of the samples were refined using sandpaper.

\section{Sorption Test}

Sample pre-conditioning: 3 specimens were prepared per weight fraction per sorption temperature. Samples were dried in the heat press for 1 hour at $55^{\circ} \mathrm{C}$ and cooled in the dessicator. Dimensions of the samples were measured using a digital caliper and initial weight of the samples was measured using an analytical balance.

Sorption Proper: The water bath was prepared by setting sorption temperature. $1000 \mathrm{~mL}$ beakers were filled with $1000 \mathrm{~mL}$ distilled water, placed in the water bath and allowed to attain constant temperature.

Samples were placed in the prepared beakers. One beaker contains 3 specimens with the same fly ash weight fraction. The samples were weighed following set time intervals. In weighing the specimens, surface water was quickly wiped off using lint-free wipes.

Post sorption: After sorption, samples were wiped with lint free wipes. Dimensions were measured and physical changes were noted.

\section{RESULTS AND DISCUSSION}

\section{A. Mineralogical Composition of CFB Fly Ash}

Fly ash is mostly composed of salts. These salts are polar in nature, making fly ash hydrophillic. Table I shows the composition of fly ash.

TABLE I: X-RAY FLOURESCENCE (XRF) ANALYSIS OF CFB FLy AsH

\begin{tabular}{|c|c|c|}
\hline Components & \multicolumn{2}{|c|}{ Composition (\%) } \\
\cline { 1 - 2 } $\mathrm{SiO}_{2}$ & 35.65 & \multirow{2}{*}{65.77} \\
\cline { 1 - 2 } $\mathrm{Al}_{2} \mathrm{O}_{3}$ & 20.12 & \\
\hline $\mathrm{Fe}_{2} \mathrm{O}_{3}$ & 10.00 & \\
\hline $\mathrm{CaO}$ & \multicolumn{2}{|c|}{21.43} \\
\hline $\mathrm{MgO}$ & 2.99 \\
\hline $\mathrm{SO}_{3}$ & \multicolumn{2}{|c|}{4.34} \\
\hline $\mathrm{K}_{2} \mathrm{O}$ & \multicolumn{2}{|c|}{1.13} \\
\hline $\mathrm{Na}_{2} \mathrm{O}$ & \multicolumn{2}{|c|}{1.08} \\
\hline $\mathrm{LOI}$ & 3.47 \\
\hline
\end{tabular}

\section{B. Diffusion Model Fitting}

Fickian model of diffusion was fitted to the water absorption data of the composite and neat resin for different temperatures. The samples are assumed to be homogenous and isotropic and the diffusivity constant along all directions. Diffusivity is assumed to be only dependent on temperature and particle loading. One dimensional diffusion (through the thickness) is also assumed.

According to Fick's law:

$$
\frac{\partial c}{\partial t}=D_{x} \frac{\partial^{2} c}{d x^{2}}
$$

where:

$c=$ specimen moisture concentration

$t=$ time 
$D_{x}=$ through the thickness diffusivity

$x=$ through the thickness dimension

The boundary conditions are as follows:

$$
\begin{gathered}
c(0<x<1,0)=c_{0} \\
c(0, t)=c_{1} \\
c(1, t)=c_{1}
\end{gathered}
$$

Solving the differential equation from [22]

$$
\frac{M_{t}}{M_{\infty}}=1-\frac{8}{\pi^{2}} \sum_{n=0}^{\infty} \frac{1}{(2 n+1)^{2}} \exp \left(\frac{-(2 n+1)^{2} \pi^{2} D_{x} t}{l^{2}}\right)
$$

where:

$M_{t}=\%$ moisture content (dry basis) at time $t$

$M_{\infty}=\%$ moisture content (dry basis) at infinite time

$l=$ thickness of specimen

and

$$
M=\frac{\text { current mass-initial mass,dry }}{\text { initial mass, dry }} \times 100 \%
$$

And according to [23], approximately:

$$
\frac{M_{t}}{M_{\infty}}=1-\exp \left[-7.3\left(\frac{D_{x} t}{l^{2}}\right)^{.75}\right]
$$

In order to fit the experimental data with the model, diffusivity and moisture equilibrium content has to determined experimentally; and from [22] fr small times:

$$
\frac{M_{t}}{M_{\infty}}=\frac{4\left(D_{x} t\right)^{1 / 2}}{l \pi^{1 / 2}}
$$

Graphing \% weight gain vs. square root of time, for small $t$, a linear part is observed before approaching constant moisture content, $M_{\infty}$ (see Fig. 1). From the slope, diffusivity is calculated as follows:

$$
D_{x}=\left(\frac{\text { slope } * l \pi^{\frac{1}{2}}}{4 M_{\infty}}\right)^{2}
$$

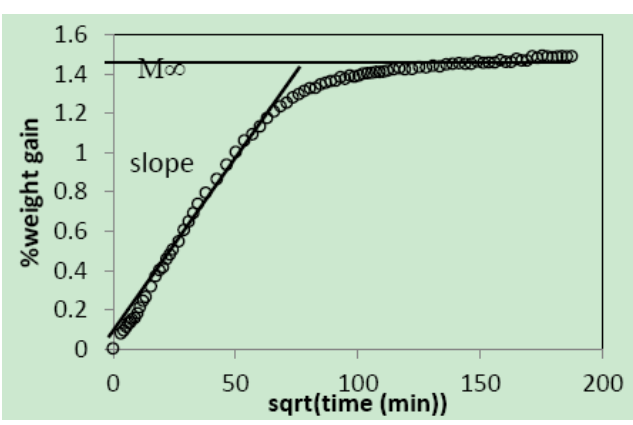

Fig. 1. Determining equilibrium moisture content and slope

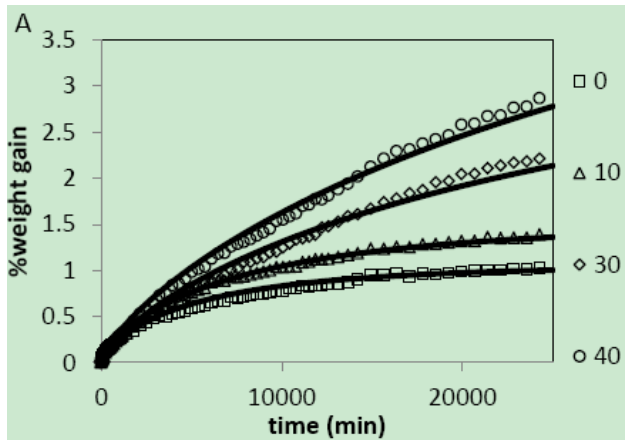

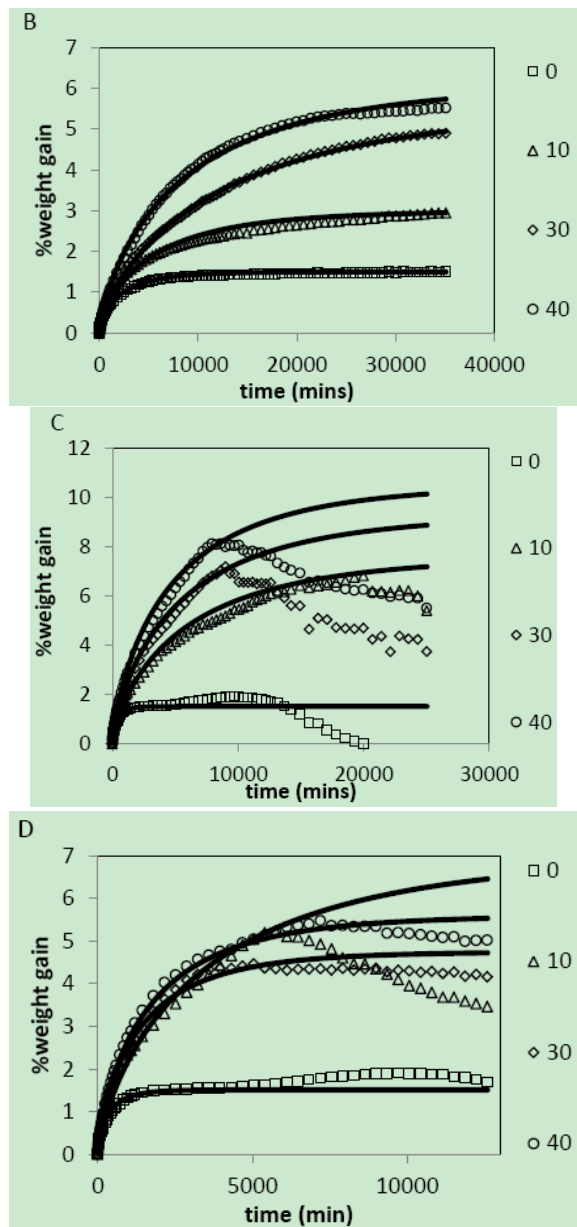

\begin{tabular}{|c|c|c|c|c|}
\hline CFB FA & Temperature & $\begin{array}{l}\text { Particle } \\
\text { loading }\end{array}$ & $M \infty, \%$ & $\begin{array}{c}\text { Diffusivity, } \\
\mathrm{m}^{2} / \mathrm{min}\end{array}$ \\
\hline \multirow{12}{*}{ Untreated } & \multirow{4}{*}{$30^{\circ} \mathrm{C}$} & 0 & 1.05 & $5.34 \mathrm{E}-07$ \\
\hline & & 10 & 1.5 & 4.19E-07 \\
\hline & & 30 & 3.6 & $1.12 \mathrm{E}-07$ \\
\hline & & 40 & 5.7 & $9.69 \mathrm{E}-08$ \\
\hline & \multirow{4}{*}{$50^{\circ} \mathrm{C}$} & 0 & 1.5 & $1.36 \mathrm{E}-06$ \\
\hline & & 10 & 3 & $5.72 \mathrm{E}-07$ \\
\hline & & 30 & 5.6 & $2.5 \mathrm{E}-07$ \\
\hline & & 40 & 6.1 & $4.8 \mathrm{E}-07$ \\
\hline & \multirow{4}{*}{$80^{\circ} \mathrm{C}$} & 0 & 1.51 & $1.11 \mathrm{E}-05$ \\
\hline & & 10 & 7.6 & $6.03 \mathrm{E}-07$ \\
\hline & & 30 & 9.3 & 5.43E-07 \\
\hline & & 40 & 10.5 & 8.74E-07 \\
\hline \multirow{4}{*}{ Treated } & \multirow{4}{*}{$80^{\circ} \mathrm{C}$} & 0 & 1.51 & $1.11 \mathrm{E}-05$ \\
\hline & & 10 & 7 & $9.15 \mathrm{E}-07$ \\
\hline & & 30 & 4.75 & $2.87 \mathrm{E}-06$ \\
\hline & & 40 & 5.6 & 2.39E-06 \\
\hline
\end{tabular}

Fig. 2. Fitting of Fickian diffusion model with experimental data; A: $30^{\circ} \mathrm{C}$, B: $50{ }^{\circ} \mathrm{C}, \mathrm{C}: 80^{\circ} \mathrm{C}$-untreated fly ash composite, D: $80^{\circ} \mathrm{C}$-treated fly ash composite.

Fig. 2A-Fig. 2D show the fit of the Fickian model to experimental data. The model is fitted for different particle loading and temperature. Table II also shows values calculated and used for model fitting. 
When the temperature is set to $80^{\circ} \mathrm{C}$, the resin and composite starts to show signs of degradation. This study is limited to moisture absorption and diffusion thus only the sorption part is considered and for data fitting, it is assumed that at the start, only diffusion occurs until maximum moisture absorption has been reached. After which, degradation and weight loss starts.

\section{Effect of Temperature}

In general, diffusivity increases as temperature increases and often related by the Arrhenius equation [24].

where:

$$
D=D^{0} \exp ^{-\Delta H / R T}
$$

$D=$ diffusivity

$D^{0}=$ frequency factor

$\Delta H=$ activation enthalpy of diffusion

$R=$ gas constant

From Table II, diffusivity increases as a function of temperature. Fitting in the Arrhenius equation, $\ln D$ is graphed vs. 1/T. A linear graph will indicate good fit to the model.

$$
\ln D=\ln D^{0}-\frac{\Delta H}{R T}
$$

Another effect of temperature is observed on the equilibrium moisture content. Equilibrium moisture content is a function of the material and relative humidity. For materials immersed in liquids, equilibrium moisture content is constant. However, for this experiment, equilibrium moisture content increased as a function of temperature (see Table II).

The increase in equilibrium moisture content might be due to the composite undergoing some changes such as matrix swelling and plasticization. When exposed to moisture, water acts a plasticizer, lowering the glass transition temperature of polymers [25]. Coupled with an increase in temperature, the matrix might have reached its glass transition temperature. Fig. 3 shows that glass transition temperature of the neat resin is $71.37^{\circ} \mathrm{C}-72^{\circ} \mathrm{C}$. In the glass transition temperature, the polymer transforms from a glassy/rigid state to a rubbery state. Matrix swelling (and cracks inside the composite) also occurred, making more moisture trapped in the composite.

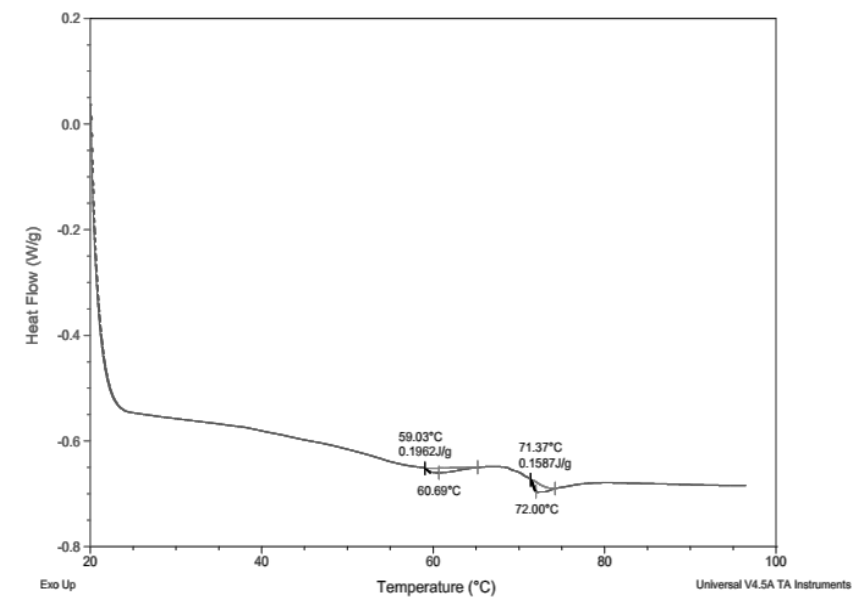

Fig. 3. Differential scanning calorimetry (DSC) analysis of neat resin.

Physical changes become evident at high temperature.
Neat resin starts to become yellowish at $50^{\circ} \mathrm{C}$ and evident signs of degradation appear when temperature is at $80^{\circ} \mathrm{C}$. Untreated fly ash composites tend to become lighter in color as temperature is increased. Also, for samples of higher loading, swelling is observed for higher temperatures.

\section{Effect of Particle Loading}

From Table II, generally, diffusivity decreases as particle loading increases. The presence of fly ash made diffusion in the composite slower. It might have provided obstruction in the pathway of water. Being porous, water absorbed also has to diffuse through the fly ash. At $80^{\circ} \mathrm{C}$, the effect of particle loading differs. Diffusivities of composites have relatively close value and are below the calculated diffusivity for neat resin sample. Excluding the diffusivity for neat resin, diffusivities of the composites at this temperature are generally increasing. These differences may be attributed to the temperature being above glass transition temperature thus causing changes to the material (and possibly degradation).

Particle loading also affected equilibrium moisture content. As seen in Table II, for untreated fly ash, as particle loading increases, equilibrium moisture content also increases. Fly ash is porous and hydrophilic, thus the presence of fly ash increased amount of water absorbed. However, for treated fly ash, the trend for equilibrium moisture cannot be clearly established but it can be noted that the percent difference between equilibrium moisture of treated and untreated fly ash increases as particle loading increase. Since fly ash is porous, it tends to absorb moisture, thus when treated, the effect on its hydrophobicity affects its ability to absorb moisture and this effect becomes more evident when particle loading is increased.

\section{E. Effect of Treatment}

Treated fly ash is characterized by scanning electron microscope (SEM). As seen in Fig. 4, the size of the fly ash decreased and became glass shard-like. The decrease in size might be due to the reaction of sulphuric acid with fly ash [26].

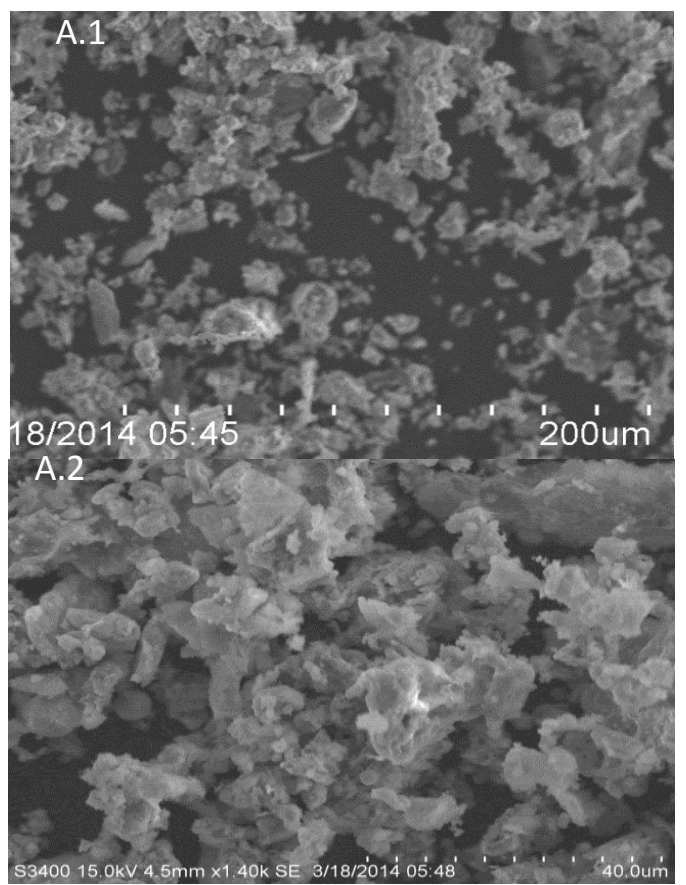




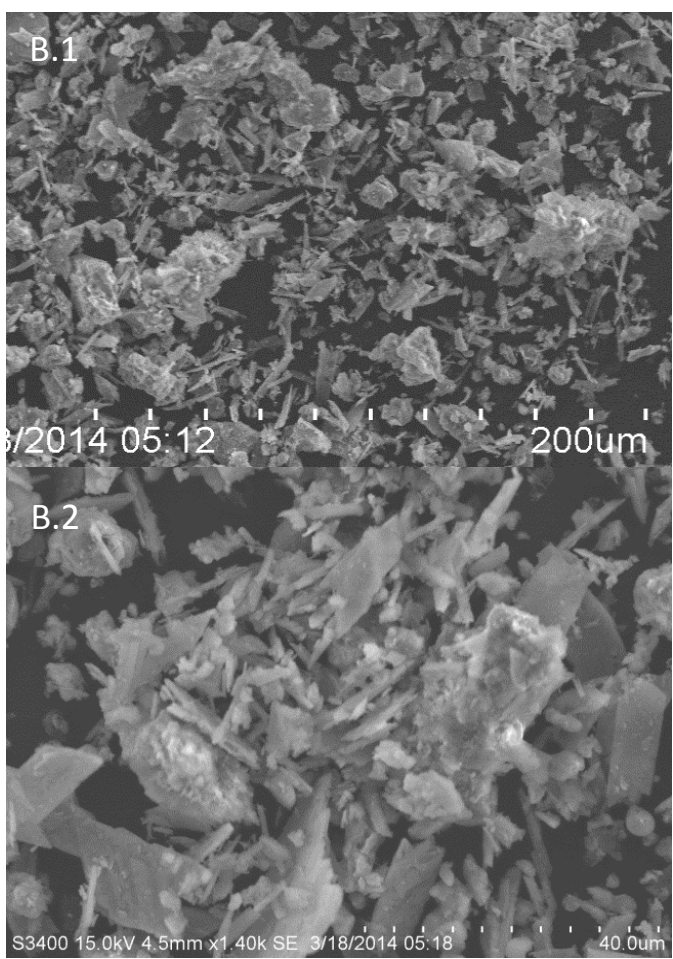

Fig. 4. Scanning Electron Microscopy (SEM) images of (A) untreated fly ash and (B) treated fly ash.

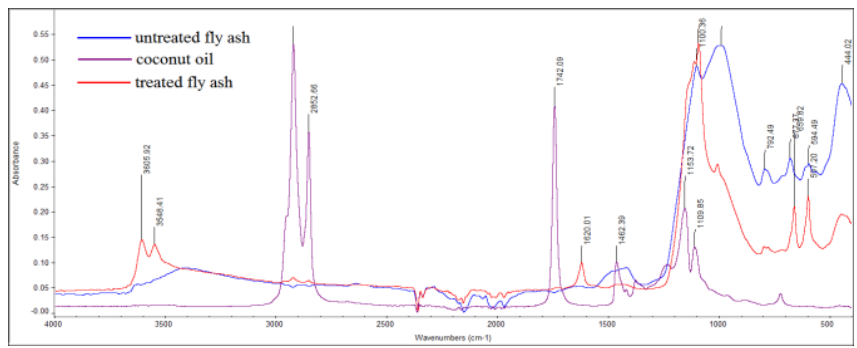

Fig. 5. Fourier Transform infrared spectroscopy (FTIR) analysis of untreated and treated fly ash and coconut oil.

Fourier transform infrared spectroscopy (FTIR) analysis (see Fig. 5) shows the functional groups present in the coconut oil, treated and untreated fly ash. Peaks at 3548 and 3605 are due to the $\mathrm{O}-\mathrm{H}$ from alcohols. Peaks at 2900 and 2853 indicate the presence of $\mathrm{CH}_{3}$ and $\mathrm{CH}_{2}$ from aliphatic compounds. These peaks are evident in coconut oil because of the saturated fatty acids. These peaks also appear for treated fly ash as the saturated fatty acids coat the fly ash. The peak at $1000 \mathrm{~cm}^{-1}$ present in untreated fly ash decreased in treated fly ash, this represent the presence of $\mathrm{SiO}_{2}$ that might have reacted with the treatment causing a decrease in absorbance at this wave number for treated fly ash [27].

FTIR results show that there are changes in the functional group of the fly ash. The acid group may have reacted with the basic filler, while the long chain ends coat the filler making the filler hydrophobic. Fig. 6 shows the change in the treated fly ash and its hydrophobicity.

When used as filler, the treated fly ash affects the diffusivity and equilibrium moisture content of the composite. Equilibrium moisture content of the composite is lowered due to the hydrophobicity of the treated fly ash while the rate of diffusion is similar until it reached the lowered equilibrium moisture content (see Fig. 7) Matrix swelling still occurred but less than the untreated fly ash composite.
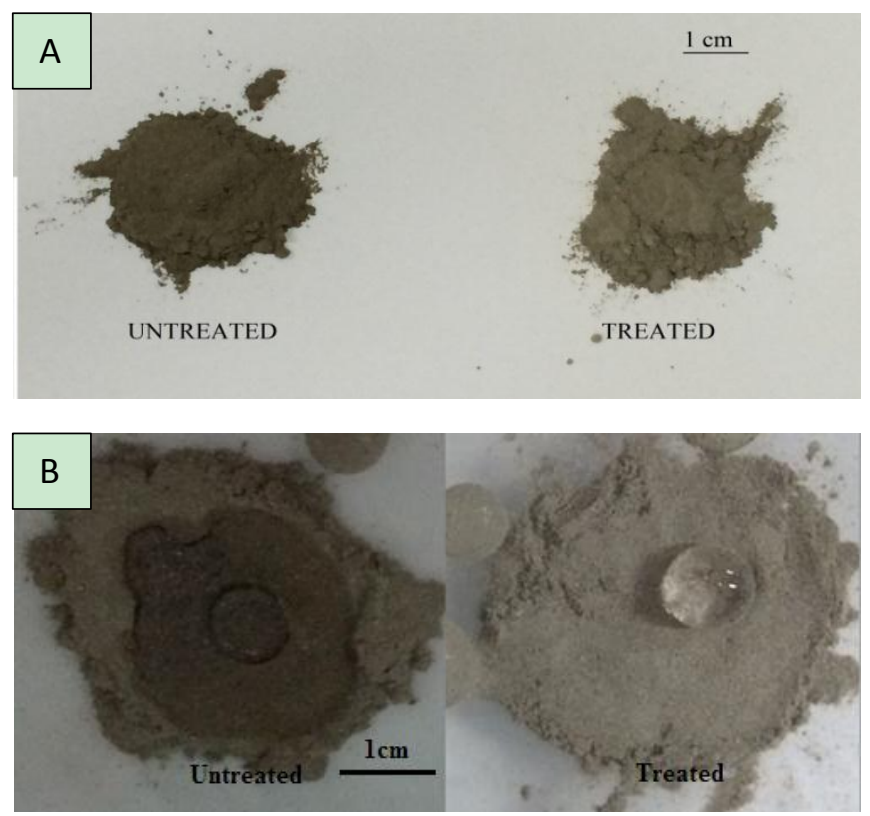

Fig. 6. Effect of treatment on fly ash (A) and its hydrophobicity (B).
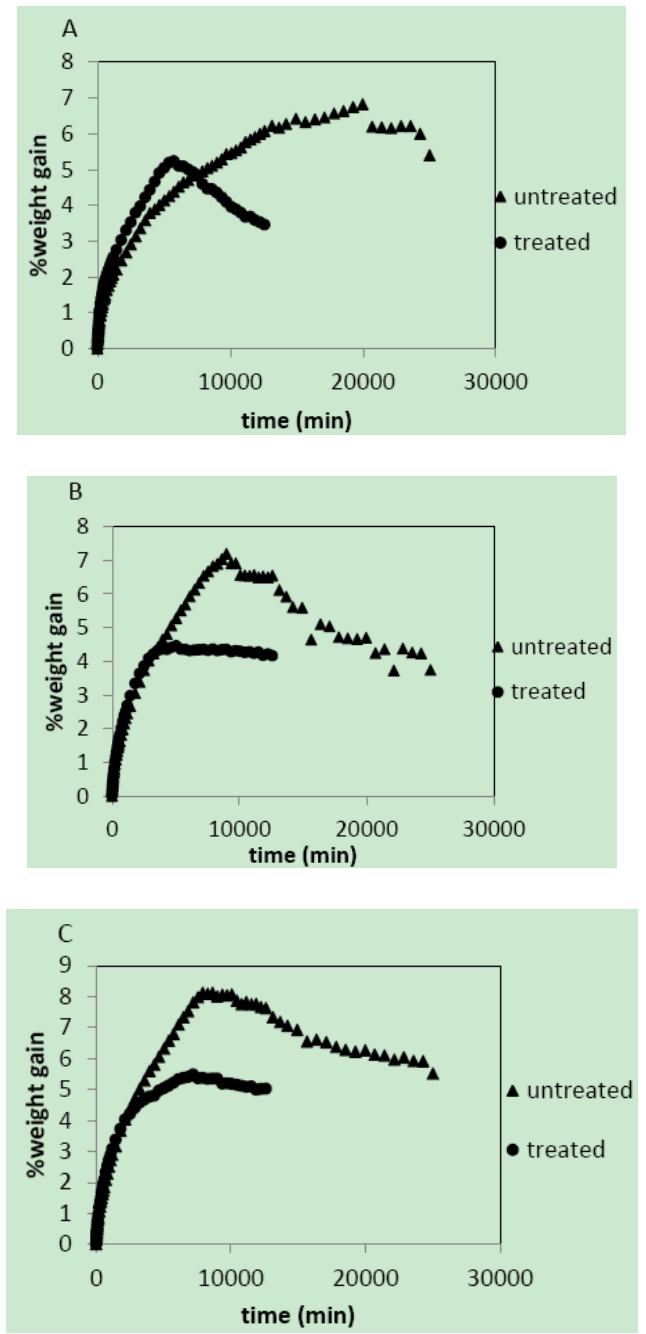

Fig. 7. Effect of treatment on moisture absorption of composite; A: $10 \%$ loading, B: $30 \%$ loafing, C: $40 \%$ loading.

\section{CONCLUSION}

CFB fly ash reinforced composite was successfully produced and its moisture absorption properties are studied.

In temperatures below glass transition temperature, one 
dimensional fickian diffusion model fits satisfactorily with the moisture absorption of orthophthalic saturated resin and its composites. Temperature affects diffusivity as modelled by the Arrhenius equation. Diffusivity increases as temperature increases. Temperature also affects equilibrium moisture content. Instead of being constant with respect to temperature, equilibrium moisture content increases as a function of temperature. This might have been due to degradation, plasticization and matrix swelling. For high temperatures, degradation is evident and swelling is observed.

Particle loading has an impact on treated and untreated fly ash composites. Its effect is more apparent on moisture equilibrium content. Fly ash, being porous and hydrophilic, increases equilibrium moisture content as particle loading increases. Particle loading also affects diffusivity but inversely. As particle loading increase, diffusion of water thru the composite becomes slower. Fly ash may have acted as obstruction and the presence of its pores may have caused overall slower diffusion as water also diffused through the fly ash.

The treatment has an effect on the properties of the fly ash and may have improved moisture absorption of the composite. As seen on the FTIR results, there is a change in fly ash functional groups. Treated fly ash also became hydrophobic from being hydrophilic. Treated fly ash composites absorbed less moisture compared to their untreated counterparts.

Studies involving the effects of different filler size, matrix type and treatment can be further investigated. Also, the effect of plasticization and degradation can be studied to gain further understanding and life cycle assessment of the material.

\section{ACKNOWLEDGMENT}

The author would like to thank professors from the Department of Chemical Engineering, University of the Philippines-Diliman especially to Dr. Terence Tumolva. Special thanks to DOST-ERDT.

\section{REFERENCES}

[1] Department of Energy. [Online]. Available: http://www.doe.gov.ph/fossil-fuels/coal

[2] Department of Energy, Philippine Energy Plan 2012-2030

[3] S. Rajaram, "Next generation CFBC," Chemical Engineering Science, pp. 5565-5571, 1999.

[4] R. Conn, K. Sellakumar, and A. Bland, "Utilization of CFB Fly Ash for Construction Applications," in Proc. the 15th International Conference on Fluidized Bed Combustion, Georgia, 1999.

[5] N. Koukouzas, C. R. Ward, D. Papanikolaou, Z. Li, and C. Ketikidis, "Quantitative evaluation of minerals in fly ashes of biomass, coal and biomass-coal mixture derived from circulating fluidised bed combustion technology," Journal of Hazardous Materials, pp. 200207, 2009.

[6] B. Steenari, S. Schelander, and O. Lindqvist, "Chemical and leaching characteristics of ash from combustion of coal, peat and wood in a 12 MW CFB - a comparative study," Fuel, pp. 249-258, 1999.

[7] M. Glinicki and M. Zielinski, "The influence of CFBC fly ash addition on phase composition," Bulletin of the Polish Academy of Sciences, pp. 45-52, 2008.
[8] I. Lecuyer, S. Gueraud, and J. Bursi, Different uses of CFB ash - EDF investigations.

[9] N. M. Jackson, S. Schultz, P. Sander, and L. Schopp, "Beneficial use of CFB ash in pavement construction applications," Fuel, pp. 1210$1215,2009$.

[10] Z. Zhang, J. Qian, Y. Chao, and C. Hu, "Use of circulating fluidized bed combustion fly ash and slag in autoclaved brick," Construction and Building Materials, pp. 109-116, 2012.

[11] N. Koukouzas, C. Vasilatos, G. Itskos, I. Mitsis, and A. Moutsatsou, "Removal of heavy metals from wastewater using CFB-coal fly ash zeolitic materials," Journal of Hazardous Materials, vol. 173, pp. 581-588, 2010.

[12] M. Singla and V. Chawla, "Mechanical Properties of Epoxy Resin Fly Ash Composite," Journal of Minerals \& Materials Characterization \& Engineering, vol. 9, no. 3, pp. 199-210, 2010.

[13] G. Akovali and C. Kaynak, "Constituent Materials," Handbook of Composite Fabrication, Rapra Technology Ltd., 2001, pp. 21-58.

[14] S. H. Aziz, M. P. Ansell, S. J. Clarke, and S. R. Panteny, "Modified polyester resins for natural fibre composites," Composites Science and Technology, vol. 65, pp. 525-535, 2005.

[15] M. de Farias, M. Farina, A. Pezzin, and D. Silva, "Unsaturated polyester composites reinforced with fiber and powder of peach palm: Mechanical characterization and water absorption profile," Materials Science and Engineering C, pp. 510-513, 2009.

[16] L. B. Manfredi, E. S. Rodriguez, M. Wladyka-Pryzbylak, and A. Vazquez, "Thermal degradation and fire resistance of unsaturated polyester, modified acrylic resins and their composites with natural fibres," Polymer Degradation and Stability, pp. 255-261, 2006.

[17] T. Pepper, "Polymer Resins," Engineered Materials Handbook, Ashland Chemical Company, pp. 90-96.

[18] Z. Sarbak and M. Kramer-Wachowiak, "Porous structure of waste fly ashes and their chemical modifications," Powder Technology, vol. 123, pp. 53-58, 2002.

[19] Y.-F. Yang, G.-S. Gai, Z.-F. Cai, and Q.-R. Chen, "Surface modification of purified fly ash and application in polymer," Journal of Hazardous Materials, vol. B133, pp. 276-282, 2006.

[20] T. Chaowasakoo and N. Sombatsompop, "Mechanical and morphological properties of fly ash/epoxy composites using conventional thermal and microwave curing methods," Composites Science and Technology, pp. 2282-2291, 2007.

[21] N. Yao, P. Zhang, L. Song, M. Kang, Z. Lu, and R. Zheng, "Stearic acid coating on circulating fluidized bed combustion fly ashes and its effect on the mechanical performance of polymer composites," Applied Surface Science, vol. 279, pp. 109-115, 2013.

[22] J. C. Rank, Mathematic of Diffusion, Oxford University Press, 1975.

[23] C.-H. Shen and G. S. Springer, "Moisture Absorption and Desorption of Composite Materials," Journal of Composite Materials, vol. 10, pp. 2-20, 1976.

[24] H. Mehrer, Diffusion in Solids, New York: Springer-Verlag Berlin Heidelberg, 2007.

[25] R.-M. Wang, S.-R. Zheng, and Y.-P. Zheng, Polymer matrix composites and technology, Cornwall: Woodhead Publishing Limited and Science Press Limited, 2011.

[26] R. Shawabkeh, M. J. Khan, A. A. Al-Juhani, H. I. Al-Abdul Wahhab, and I. A. Hussein, "Enhancement of surface properties of oil fly ash by chemical treatment," Applied Surface Science, 2011.

[27] O. Celik, E. Damci, and S. Piskin, "Characterization of fly ash and it effects on the compressive strength properties of Portland cement," Indian Journal of Engineering \& Material Sciences, pp. 433-440, 2008.

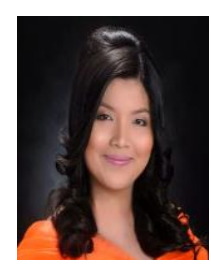

Sakura E. Onishi is a member of Philippine Institute of Chemical Engineers and University of the Philippines Chemical Engineering Society Inc. She was born in Valenzuela, Philippines on January 3, 1991. She received her master and bachelor of science degree in chemical engineering from the University of the Philippines-Diliman in 2014 and 2012 respectively. She passed the November 2012 chemical engineering board exam. 
